Title:

Author(s):

Submitted to:
The Application of Microrobotics in Warfare

Johndale Solem, DDT

DOE Office of Scientific and Technical Information (OSTI)
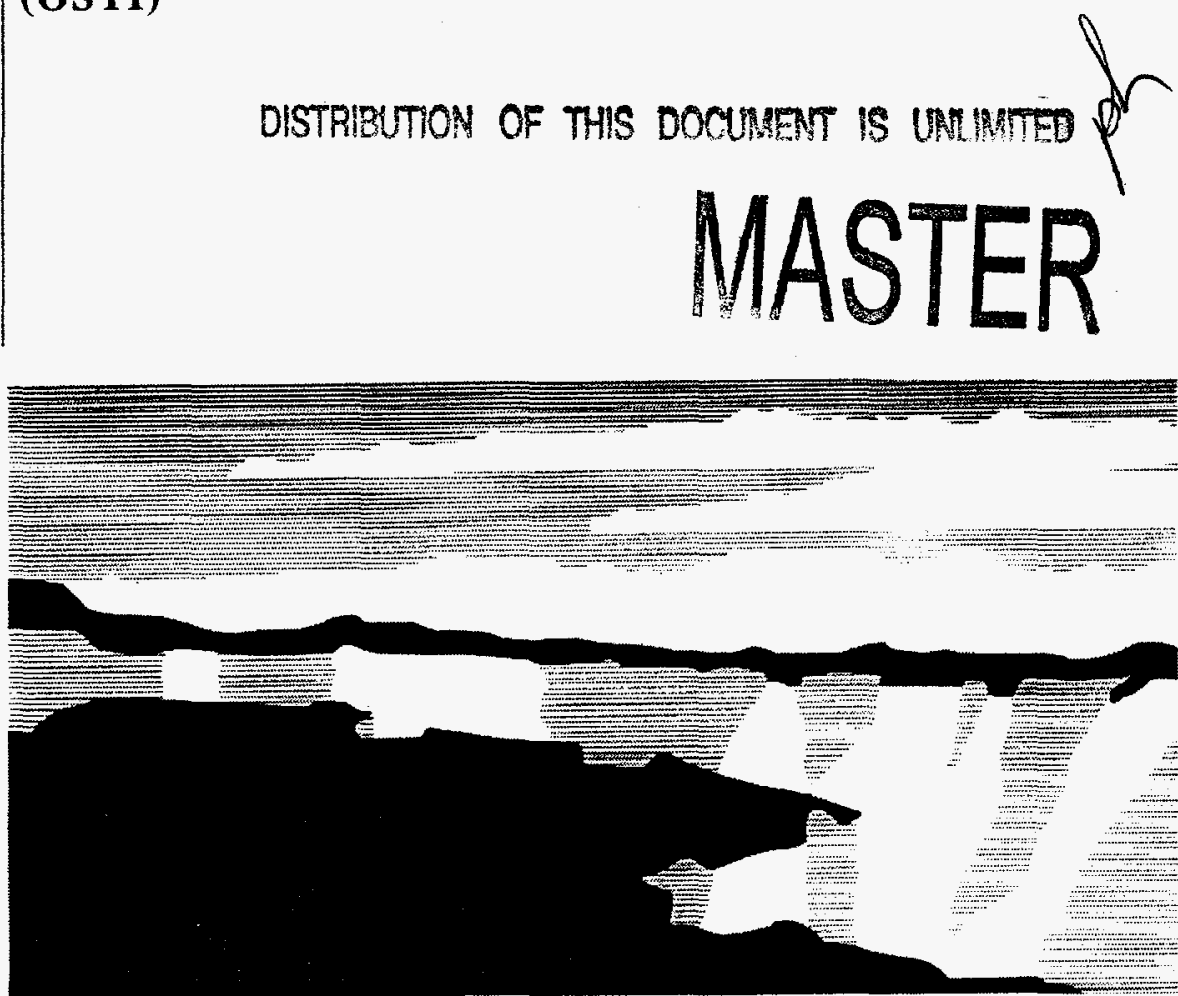

Los Alamos National Laboratory, an affirmative action/equal opportunity employer, is operated by the University of California for the U.S. Department of Energy under contract W-7405-ENG-36. By acceptance of this article, the publisher recognizes that the U.S. Govemment retains a nonexclusive, royaltytree license to publish or reproduce the published form of this contribution, or to allow others to do so, for U.S. Government purposes. The Los Alamos National Laboratory requests that the publisher identity this article as work performed under the auspices of the U.S. Department of Energy. 


\section{DISCLAIMER}

Portions of this document may be illegible in electronic image products. Images are produced from the best available original document. 


\section{DISCLAIMER}

This report was prepared as an account of work sponsored by an agency of the United States Government. Neither the United States Government nor any agency thereof, nor any of their employees, makes any warranty, express or implied, or assumes any legal liability or responsibility for the accuracy, completeness, or usefulness of any information, apparatus, product, or process disclosed, or represents that its use would not infringe privately owned rights. Reference herein to any specific commercial product, process, or service by trade name, trademark, manufacturer, or otherwise does not necessarily constitute or imply its endorsement, recommendation, or favoring by the United States Government or any agency thereof. The views and opinions of authors expressed herein do not necessarily state or reflect those of the United States Government or any agency thereof. 


\title{
The Application of Microrobotics in Warfare
}

\author{
Johndale Solem*
}

\begin{abstract}
This is the final report of a one-year, Laboratory-Directed Research and Development (LDRD) project at the Los Alamos National Laboratory (LANL). The project sought to conduct a detailed theoretical study of military microrobot requirements and performance in conflict situations. The study was directed toward construction of a proof-of-concept prototype with attention to its eventual mass manufacture using microlithographic fabrication techniques. The study included design and performance assessment of payloads for the microvehicle, which might include special sensors and data processing equipment for gathering intelligence, or electrical, mechanical, and chemical disrupters of various sorts.
\end{abstract}

\section{Background and Research Objectives}

Progress in the development of microlithographic techniques for fabrication of motors, pumps, flexors, and other actuators, as well as chemical, electromagnetic, and mechanical sensors, has stimulated much speculation about the application of such devices in warfare. One area of speculation and research has dealt with construction of small -- nearly undetectable by dint of size -- sensor packages, and their use to collect intelligence concerning troop movements and other activities within enemy territory. These nonmotile robots could be dispensed by a low-observable unmanned air vehicle (UAV) and could be interrogated from time to time by the same aircraft [1]. A second area of speculation and research has dealt with construction of microrobots capable of moving themselves. For the intelligence mission, the motile robot would avoid the use of an invasive aircraft, which might provoke an escalation of the conflict. An underlying premise is that these devices could be manufactured in large quantities and at low cost, much the way integrated circuits are manufactured today. High probability of mission success could be ensured by deploying a multitude of microrobots, each with a finite chance of accomplishing its assigned task.

\footnotetext{
* Principal investigator, e-mail: jxcs@lanl.gov
} 
The near-term product of this project was a theoretical study of microvehicle requirements. The study was directed toward scoping design of prototype devices with attention to the potential for mass manufacture using microlithographic fabrication techniques. The study included design and performance assessment of payloads for the microvehicle, which might include special sensors and data processing equipment for gathering intelligence, or electrical, mechanical, or chemical disrupters of various sorts. The most important consideration for the motile microrobot was deemed to be the energetics of its locomotion [2].

\section{Importance to LANL's Science and Technology Base and National R\&D Needs}

This project supports Los Alamos core competencies in analysis and assessment as well as theory, modeling, and high-performance computing. The study was intended to establish Los Alamos as a leader in the area of microrobotic-warfare research. Microrobotics research is also attractive for its dual-use potential.

\section{Scientific Approach and Results to Date}

I elected to team up with investigators at RAND Corporation, who were also pursuing microrobotics out of internal funds. In this collaborative analysis, we decided that the nearterm objective should be a small flying device for surveillance and counter proliferation. Rather than immediately pursuing the microlithography scale using electrostatic motors, we decided to investigate gram-scale devices using electromagnetic motors. We analyzed several alternative designs for microflyers and even evaluated some lifting systems on the test stand. RAND also evaluated some microimaging devices to be carried on such a platform.

\section{Propulsion and Lifting Studies}

A series of three short experimental campaigns were conducted at the Los Alamos Target Fabrication Facility using the smallest available commercial motors.

Trihedral Blades: The motor for the initial experiments [3] was a Namiki 7CE-1701, a coreless samarium-cobalt design alleged by its manufacturer to produce a power of $40 \mathrm{~mW}$ at $7000 \mathrm{rpm}$. This motor, which weighed $2 \mathrm{~g}$, was found to be capable of much higher power when greater-than-rated voltages were applied, although the greater power was produced at a somewhat reduced efficiency. To mitigate the rotor-blade end effect at the appropriate Reynolds number, an aspect ratio of at least 8:1 was required. Two trihedral blades were tested, both were constructed from $34.3 \mu \mathrm{m}$ titanium sheet. The long blade was $5.20 \mathrm{~cm}$ and weighed $26.7 \mathrm{mg}$ with an area of approximately $1.72 \mathrm{~cm}^{2}$. The short blade was $4.74 \mathrm{~cm}$ and weighed $24.3 \mathrm{mg}$ with an area of approximately $1.56 \mathrm{~cm}^{2}$. The pitch was set at approximately 
$30^{\circ}$ and was identical for each blade. The test-stand experiments showed that thrusts as high as $3.5 \mathrm{~g}$ could be obtained, thus the motor was quite capable of lifting itself and a payload in a direct rotary-wing design and capable of propelling high-performance, fixed-wing designs. Derivative measurements of the lift coefficient $C_{l}$ and the drag coefficient $C_{d}$ suggested there was yet some room for improvement in the blade design.

Cylindrical Section Blades: The motor for this test series [4] was a Namiki 6CE-1501, which at $1.8 \mathrm{~g}$ was the smallest manufactured motor. It was fitted with a $1.775-\mathrm{cm}$ radius cylindrical-section titanium blade and produced a thrust of $3.25 \mathrm{~g}$ at $5 \mathrm{~V}$, which was nearly twice its weight. Direct measurement of thrust and angular velocity gave a lift coefficient $\mathrm{Cl}_{\mathrm{l}}=$ 1.26. Derivative measurements gave a drag coefficient $C_{d}=0.84$, somewhat disappointing, but probably owing to exaggerated motor efficiency. The thrust was proportional to the $2 / 3$ power of the electrical input power from 0.01 to $1.25 \mathrm{~W}$, suggesting that motor efficiency is nearly constant in this range.

Cylindrical Section Blade with Reduction Gear: For rotary-wing aircraft, the lift is jointly proportional to the $2 / 3$-power of motor mechanical power and the 1/3-power of the wing area [5]. So there is some advantage to increasing the wing area and using a reduction gear to match its annular velocity to the motor's power maximum. A Namiki 7CE-1701 motor attached to a 4.2-cm radius cylindrical-section titanium blade through a 4.16:1 reduction gear produced a thrust of $6.41 \mathrm{~g}$ at $4.5 \mathrm{~V}$. Direct measurement of thrust and angular velocity gave $C_{l}=1.49$. Derivative measurements gave $C_{d}=0.855$. Thrust was proportional to the 2/3-power the electrical input as expected; however, plots of thrust versus potential and stroboscopic observations suggested some changes in lift and drag as a function of angular speed, probably change in shape of the wing.

In summary, our investigation of commercially available motors indicated that they could be used to power quite small and effective semi-autonomous aircraft, but the resulting size advantage was less than an order-of-magnitude improvement over what was available to hobbyists. Massachusetts Institute of Technology Lincoln Laboratories somewhat independently came to a similar conclusion [6].

Being unsatisfied with the size scales offered by off-the-shelf power systems as an interpolation between current technology and the full potential of microlithography, we investigated the limits of electromagnetic motors in the experimental stages of development. We found that Toshiba had developed a commutatorless motor whose mass was $0.15 \mathrm{~g}$, more than a factor of 10 less than the commercially available motors [7]. A major fraction of this mass reduction was owing to the elimination of the commutator, which was a logical step as the motor would be completely controlled by an integrated circuit anyway. A power maximum of $40 \mathrm{~mW}$ was imputed to this motor, making it the equivalent of the Namiki 
commercial motor. We attempted to purchase some such motors from Toshiba, but they declined, as such a sale of experimental devices was proscribed by company policy. We considered building several similar motors at Los Alamos, but the funds were not available.

\section{Electrical Power}

In our original scoping study, we had planned to use thin-film lithium batteries [8]. These devices utilize different cathodes depending on the voltage requirements, but with a $\mathrm{V}_{2} \mathrm{O}_{5}$ cathode, which seemed to serve our purposes, they offer a specific energy of about $1.6 \mathrm{x}$ $10^{3} \mathrm{~J} \mathrm{~g}^{-1}$. Beside their energy capacity, their thin-film design allows them to be used as structural elements such as the skin of the airfoils. A problem that emerged during our research was the polarization of all types of batteries. Polarization is the tendency for reactants to accumulate at the electrodes when the battery is drained rapidly. The accumulation causes the internal resistance to increase, hence the power will drop-off until the load is disconnected and the reactants are allowed to diffuse away from the electrodes. Polarization is less pronounced in storage batteries, of which the thin-film design is an example. Nevertheless, the thin-film lithium battery maintains its low internal resistance only when discharged over many hours. We have conducted preliminary investigations of combining technologies with socalled "high-rate" lithium batteries.

\section{Sensor Design}

Of the many possible sensors to be carried by the microflyer, it seemed the most important was an imaging sensor either in the infrared or visible. R. Zwirn of RAND designed a visible-band video camera $3.5 \mathrm{~mm}$ in diameter, weighing $0.7 \mathrm{~g}$, with a power consumption of $0.5 \mathrm{~mW}$. The device could be used in a wide-field mode (approximately $89^{\circ}$ $x 66^{\circ}$ ) with low resolution (approximately $30 \mathrm{mR}$ ) for navigation and awareness of its surroundings, or it could be used in narrow-field mode (approximately $1^{\circ} \times 1^{\circ}$ ) with low resolution (approximately $0.2 \mathrm{mR}$ ) for close-up inspection of documents, apparatus, etc. Remarkably, all the components for this camera are available commercially. An infrared version would necessarily be larger because of it must provide room for a cooling system.

Some chemical sensors were also commercially available, but mostly for medical analysis and diagnosis. The extension of these sensors to neurotoxins and biological agents seemed straightforward but would require a good deal of development.

Acoustical sensors with weight of approximately $0.05 \mathrm{~g}$ and power consumption of less than $5 \mathrm{~mW}$ seem well within the scope of present technology. 
Communications chips capable of sending $10^{5} \mathrm{bit} \mathrm{s}^{-1}$ on a $30 \mathrm{GHz}$ carrier weigh in at less than $0.1 \mathrm{~g}$ [9]. The radio-frequency power required for $10 \mathrm{~km}$ range is about $30 \mu \mathrm{W}$, assuming a $1 / 2$ wave dipole for transmission and a $10 \mathrm{~cm}$ receiving dish.

\section{Flyer Design}

We investigated four fundamentally different systems for providing lift, propulsion, and control: (1) fixed-wing microflyers, (2) rotor-wing microflyers, (3) microairships, and (4) passive microflyers.

Fixed-Wing: Based on some improvement of the lift-to-drag ratio ( $/ / \mathrm{d})$ of the blades used in the experiments described above, it seemed reasonable that an aircraft carrying sensors totaling $1 \mathrm{~g}$ could be built with a total weight of $4 \mathrm{~g}$. A $10 \mathrm{~cm}^{2}$ wing with aspect ratio of 10:1 and Reynolds number of approximately $3 \times 10^{4}$ should have $\mathrm{Cl}$ of approximately 9 and $1 / \mathrm{d}$ of approximately 12. The cruising speed would be about $900 \mathrm{~cm} \mathrm{~s}^{-1}$, which would be enough to buck modest winds, and perhaps too much for some missions requiring a lot of maneuver.

Rotary-Wing: Because of the requirements for superior performance and the results of test stand measurements with Namiki motors, we analyzed designs for the rotary wing aircraft using the specifications claimed for the Toshiba experimental motor described above. Using two counter-rotating wings with a motor for each, we should obtain a lift of $1.5 \mathrm{~g}$ with a motor weight of $0.3 \mathrm{~g}$. Ignoring polarization, off-the-shelf button battery technology offers about 20 $\mathrm{mW}$ in $2 \mathrm{~g}$. Adding the communication gear $(0.1 \mathrm{~g})$, a video sensor $(0.7 \mathrm{~g})$, and structural elements $(0.2 \mathrm{~g})$, the total power drain is about $80 \mathrm{~mW}$. Taking a chemical to mechanical efficiency of $1 / 3$, the endurance should be about 5 minutes. This should be sufficient to explore about $300 \mathrm{~m}$ of rooms and hall inside a building, assuming a translational speed of approximately $100 \mathrm{~cm} \mathrm{~s}^{-1}$.

Microairships: For the surveillance mission inside a building or structure where air currents are minimized, we investigated the possibility of using a small lighter-than-air vehicle. Such a device would have exceptionally long endurance and could hover indefinitely for the purpose of close-in intelligence collection -- reading documents, inspecting apparatus, etc. Assuming the imaging apparatus, communications gear, battery, and Toshiba motor described above, combined with about $0.4 \mathrm{~g}$ of structure and controls (the envelope could be film of approximately $10^{-4} \mathrm{~g} \mathrm{~cm}^{-2}$ ), the total airship weight could be $1.8 \mathrm{~g}$. When inflated with hydrogen, it would displace approximately $1700 \mathrm{~cm}^{3}$, and could achieve a speed of approximately $200 \mathrm{~cm} \mathrm{~s}^{-1}$ at $13 \mathrm{~mW}$ power consumption assuming a $10-\mathrm{cm}$ diameter. Since the envelope would be nearly transparent, we expect the device to be quite stealthy despite its relatively large size. 
Passive Microflyers: At the Defense Advanced Research Projects Agency (DARPA) Technology-Driven Revolutions in Military Operations Workshop (December 1992), considerable discussion was devoted to passive devices that could remain aloft for an extended time after being delivered by some stealthy mother vehicle. An autorotating maple-seed type structure offers a considerable advantage over a conventional parachute as its wing area can be 7 to 10 times smaller than the equivalent disk of a parachute while falling only $20 \%$ faster. Having no propulsion, this kind of device could have a total weight of $0.3 \mathrm{~g}$ with a wing of approximately $1.5 \times 5 \mathrm{~cm}$, and the scanning provided by the rotation could be adapted to some simplified video and acoustic sensors.

\section{References}

1. Hundley, R. and E. Gritton, "Future Technology-Driven Revolutions in Military Operations," RAND Documented Briefing, DB-110-ARPA (RAND, Santa Monica, 1994).

2. Solem, J., "On the Motility of Military Microrobots (U)," Los Alamos National Laboratory Report LA-12133 (U), (1991).

3. Solem, J., "Experiments with Trihedral Blades for Small Flying Devices", Los Alamos Report LA-UR 95-1396 (1995).

4. Solem, J., "Experiments with Cylindrical Section Blades for Small Flying Devices," Los Alamos Report LA-UR 95-1395 (1995).

5. Solem, J., "Experiments with Cylindrical Section Blade and Reduction Gear for Small Flying Devices", Los Alamos Report LA-UR 95-1395 (1995).

6. Vlajinac, M., "Micro UAV", Presentation to ARPA, 23 May, 1995.

7. Itoh, T., JEE, 58-62 (1993).

8. Kanehori, K., K. Matsumoto, K. Miyauchi, and T. Kudo, Solid State lonics 9,10, 1445 (1983); J. Bates, G. Gruzalski, N. Dudney, C. Luck, X. Yu, and S. Jones, "Rechargeable Thin-Film Microbatteries," Oak Ridge National Laboratory Preprint (1993).

9. Hundley, R. and E. Gritton, "Future Technology-Driven Revolutions in Military Operations," RAND Documented Briefing, DB-110-ARPA (RAND, Santa Monica, 1994). 